\title{
The Community-Based Action Research Assignment: Catalyzing Inclusive Leadership Action in a Multicultural Leadership Class
}

\author{
Leigh E. Fine
}

\begin{abstract}
To better meet the learning objectives in a multicultural leadership class, I developed an assignment that uses action research and community-based research as frameworks for the course's culminating assignment. Called the Community-Based Action Research (CBAR) assignment, the experience invites students to develop research questions related to inclusion, connect with community partners to find the answers to these questions, then share their results through interactive dialogue with colleagues. Here, I discuss the structure and implementation of the CBAR. I then reflect on student interviews and completed CBARs to illustrate the assignment's potential to support course learning outcomes, as well as its limitations.
\end{abstract}

\section{Introduction}

As our world becomes more interconnected, the skills and abilities needed to interact with those from different backgrounds is becoming a necessity for the practice of effective leadership (Holt \& Seki, 2012; Karim, 2003; Soria, Snyder, \& Reinhard, 2015). However, teaching multicultural leadership to undergraduate students can be difficult (Fine, 2017, 2015; Karim, 2003). Attempts to explore transnational leadership differences can easily fall into a study of sophisticated stereotypes (Bird \& Osland, 2006). Such efforts typically focus on avoiding multicultural conflict as opposed to building true coalitions toward transformative leadership ends. It can be difficult for students to recognize cultural differences apart from nationality, as well. Other social identities, such as race, class, gender, age, sexuality, and religion also affect life experience and the practice of leadership, but may not be considered meaningful dimensions of difference in some leadership curricula (Ruderman \& Ernst, 2010).

The obstacles encountered teaching multicultural leadership issues can be further exacerbated when working with a culturally-homogenous population, who may have trouble seeing and articulating the importance of culture in their leadership relationships (Fine, 2015; Goodman, 2011). Despite students' increasing awareness of the influence of social identities on lived experience, I still notice that students in my multicultural leadership class, particularly those from privileged social identities, still find ways to distance themselves from the realities of those whose realities do not match their own (Kimmel, 2002). It is one thing to speak in a classroom about how speaking with those from different backgrounds is a good idea; it is yet another to explore whether everyone in the learning community has interacted with someone of a different social identity since the beginning of the course.

To address the potential gap between knowing inclusion is important to leadership and putting its associated skills into practice, I developed an assignment in my multicultural 
leadership course that asked to students to identify an issue related to diversity, inclusion, and / or privilege that is linked to leadership. Students completed a Community-Based Action Research (hereafter CBAR) assignment which tasks them with conducting original research to answer their question. Using the high-impact educational practice of undergraduate research (Kuh, 2008), CBAR prompted students to critically examine issues related to multicultural leadership. Then, using the data collected, the action research framework asks student researchers to propose, develop, and implement plans that enact positive social change (Komives, Wagner, et al., 2009; Sagor, 2011; Stringer, 2014). Here, I provide a theoretical framework for the assignment, summarize the assignment's content and context, and explore potential revisions that could further contribute toward developing multi-culturally competent undergraduate leaders.

\section{Background and Theoretical Framework}

Setting: Learning Objectives, Institution, and Student Population. Good curricular design first considers the learning objectives of the course in concert with the students' learning needs (Seemiller, 2016). I developed the CBAR for a sophomore-level leadership course, Culture and Context in Leadership, that focuses on multicultural leadership and intercultural competence. The course is the second in a four-course interdisciplinary Leadership Studies minor sequence in the Staley School of Leadership Studies at Kansas State University. The primary learning objectives of Culture and Context in Leadership are: "Understand the impact of cultural identity, life experiences, and world views on leadership relationships as it relates to privilege and inclusion," and, "Practice inclusive leadership through advocacy for social change."

The setting contributed to the development of CBAR to meet the course's learning objectives. The relative homogeneity of the student body - the institution is 77 percent white and 70 from in-state - necessitates developing an assignment where students are asked to engage directly with those of various social identities. The assignment also strives to meet course learning objectives both through the focus on privilege and inclusion, but also through the development of an action plan (Komives, Wagner, et al., 2009). Students are asked to not only research their questions, but to think about how they might act on this information, as will be described in further detail below.

Experiential Learning and Multicultural Leadership. Although there are several pedagogical approaches to teaching multicultural leadership, immersion and direct contact can have a profound influence on students. The need for contact has a theoretical basis in Berger and Luckmann's exploration of the social construction of the cultural other: "In the face to face situation, the other is fully real" (1966, p. 29). Research on shifting attitudes toward cultural groups supports the assertion that a unique appreciation for the other transpires through direct contact (Li, Mobley \& Kelly, 2013; Roper \& Halloran, 2007). If exposed to diverse populations, students are then more likely to take on leadership roles in multicultural groups (Lisak \& Erez, 2014).

Fostering direct contact for students with diverse populations is crucial to meeting multicultural leadership learning objectives for two reasons. First, the practice of leadership 
centered on social change is best practiced in concert with others as opposed to presuming what others' needs are (Clayton, 2010). If the assignment asks students to engage in inclusive social change, students run the risk of presuming what form of inclusive change might look best for another group if they do not first interface meaningfully with others. Second, direct contact can bring students face-to-face with the abstract concept of privilege which otherwise might render them oblivious to the needs of diverse community partners. Privilege or "access to resources based solely on [a] person's status" (Cullen, 2008, p. 28), can be difficult for students with advantaged social identities to identify, much less challenge (Cullen, 2008; Goodman, 2011). Coming into direct contact with how privilege affects the experiences of people from different social identities can give students the ability to access different realities, catalyzing potential social change.

Social Change and Inclusive Leadership. Some of the most pernicious leadership challenges in the world today revolve around questions of diversity, multiculturalism, and global engagement (Holt \& Seki, 2012; Karim, 2003; Soria, Snyder, \& Reinhard, 2015). Because social systems are largely set up by those in privileged positions to maintain their disparate access to social resources, there is often an intense pressure to maintain the status quo (Cullen, 2008; Marcuse, 1964). Such social systems can be detrimental to the exercise as leadership, as people feel unheard (Komives, Lucas, \& McMahon, 2013) and problematic power relations are left intact (Choo \& Ferree, 2010).

These challenges of multicultural leadership require both knowledge of and appreciation for difference to best create the common good (Komives, Lucas, \& McMahon, 2013). In the context of the course, it is not enough that students exhibit an awareness of multicultural issues, or even the competence to interface with others who are different. The course's stated learning objectives call the students to take a principled stance on questions of inclusion, asking them to create change that allows more individuals to access the emancipatory potential of leadership. Action for social change is paramount in practicing inclusive leadership, as some of the most daunting inclusion challenges are systemic barriers to full social and civic participation that demand intervention (Choo \& Ferree, 2010; Chrislip \& O’Malley, 2013).

Community-Based Research and Action Research. Undergraduate research has been identified as a high-impact practice that generates deep student learning (Kuh, 2008). I knew I wanted to craft a learning experience for the course that prompted students to discover for themselves the mechanisms of privilege and inclusion that also asked them to engage with others beyond the walls of the classroom. Community-based research and action research seemed to be good theoretical fits for the assignment. (Though there is some disagreement in the literature as to whether these are two distinct approaches, I separate them here to emphasize what I see as their helpful component parts.) Community-based research minimizes the distance between researcher and subject, encouraging those collecting data to embed themselves in the communities they wish to examine (Fontaine, 2006). This approach emphasizes collaboration with community partners, working with them to develop questions of mutual interest (Dallimore, Rochefort, \& Simonelli, 2010). Students engaging in community-based research are encouraged to view those being researched not as subjects, but as collaborators with whom they are cocreating knowledge and awareness. 
Given the course's learning objective of catalyzing positive social change, action research principles also influenced the development of the assignment. Action research emphasizes doing research with the end of applying the results toward positive change (Sagor, 2011). It differs in character from professional research (Buroway, 2005) - that is, research that is largely positivist and strives to be values-detached - as it is explicitly subjective and meant to be put into practice. Action research emphasizes the researcher making a value judgment about what end is desirable, then gearing inquiry toward finding the best methods to achieving this good. Action research emphasizes everyday people using data and information to make conscious decisions about how to change their communities for the better (Stringer, 2011).

\section{The CBAR}

Prior to the assignment, students are placed into semester-long discussion groups of four to five people formed by the instructor based on an assessment tool filled out at the start of the term. Groups are formed based on answers to questions related to attitudes on various social issues, ensuring demographic and ideological diversity. Once groups are formed, the students begin work on the CBAR throughout the semester. The CBAR structure primarily borrows from Fontaine's (2006) action research model, with an added first step of preparation (University of Maryland Division of Student Affairs, 2015). The preparation step is added to ask students to reflect on the importance of the experience and to develop a strong research question. In the preparation phase, students are asked to complete a worksheet that tasks them with developing a research question related to issues of privilege, inclusion, and / or cross-cultural leadership that interests them, as well as how they might plan to explore their question in terms of methods.

In class, we spend a week's time, or approximately three hours, discussing the CBAR's rationale and objectives, exploring the various methods at students' disposal, and engaging in discussions of ethical and responsible research. This time also provides the instructor the space to clarify standards and expectations, as well as to discuss the reciprocal relationship at the center of the CBAR (Fontaine, 2006). The CBAR deliberately uses the phrase "community partner" throughout to refer to those whom the students are studying, interviewing, or working with to encourage students to view them as active collaborators in the research students are conducting.

Upon completion of their preparation phase, students enter the fact-finding phase. In this part of the CBAR, students execute their approved method. For instance, if students select surveys, they are expected to obtain no fewer than twenty responses; for interviews, students are asked to speak with at least two people not enrolled in the course for at least an hour's time each. These are minimum standards, and nearly all student groups exceed these benchmarks by the end of the experience. Students are told that part of good leadership is also functioning within their own groups as well, and that dividing up work will be their responsibility. Students meet with the instructor in group meetings at least twice throughout the fact-finding process: once after the completion of the preparation worksheet, and once during data collection before the presentation of findings.

The CBAR culminates in the presenting findings stage, where students compose two papers and present findings to the course. The papers are meant to provide an opportunity to reflect on the experience, the learning that occurred, the connections to multicultural leadership, 
and the need to act on the findings unearthed. The first paper, whose grade value comprises the bulk of the points for the experience, is a group paper that explores their CBAR research question. In the group paper, the students must: 1) introduce their research question, convince the reader of its relevance, and explain its link to inclusive leadership; 2) provide a brief literature review of related news or scholarly articles, one per group member, that points to what they might find as they execute the CBAR or frames their research question as compelling; 3 ) explain what methods they selected and why they selected them; 4) provide a synopsis of their findings; and 5) develop an action plan to improve the world - along with their community partners - for the greater social good. Each section of the group paper has a suggested length approximately two pages, meaning that a group of five students can be expected to contribute, on average, two pages each. Groups are permitted to divide the needed work to compose the group paper in whatever way they best see fit.

In addition to the group paper, students are asked to compose an individual, two-to-threepage reflection paper detailing their personal experience with the CBAR. This paper asks students to explore both the personal relevance of their group's efforts, what they individually plan to do - if anything - based on their learning from the CBAR experience, and how they felt the group worked well together. The individual paper provides some space for individual reflection both on the findings, as well as on how the student exercised inclusive leadership with their groupmates in the context of the assignment.

Based on their CBAR results, groups construct a presentation for their colleagues to present their findings in-class. Each group is given a thirty-minute time block, but the assignment notes is their responsibility to fill no more than ten minutes of that space. The other two-thirds of the presentation time, groups are asked to consider how to give the meaningmaking process back to their student colleagues in class through discussions, activities, debates, or simulations. It is expected that the presentations should not only communicate the group's findings to the other students in class, but also give their colleagues the space to explore the relevance of the CBAR to their own lives.

Finally, students grade each other on their participation as another component of the course grade. After the completion of the CBAR, students are asked to rate how their group worked together on a scale of zero to one hundred. The scores within each group are averaged, then multiplied by the number of total students in the group and rounded up to the nearest whole number. Groups are then told they have that many points to distribute to everyone in the group, including themselves. Their final participation scores will be an average of everyone's scores for them, including their own. This method of grading can to difficult, authentic, and productive dialogues in groups that had interpersonal challenges during the assignment which the instructor can facilitate if necessary.

Examples of CBAR-Driven Change. For three years, I have used the CBAR in my multicultural leadership class to enhance students' multicultural capacities and facilitate inclusive social change. In this span of time, several CBAR groups have created long-lasting change, both on campus and in the local community. Here, I share the stories of two groups that best highlight the potential for CBAR to catalyze inclusive social change. 
The first CBAR group developed the research question, "What is it like to navigate the Kansas State University campus with a physical disability?" As all group members identified as able-bodied, they were unaware of the services available to their colleagues who were not privileged on the identity dimension of ability. For data collection, the students partnered with the Access Center, the on-campus unit who works with all university community members who may require reasonable accommodations. They interviewed student colleagues with physical disabilities, both temporary (such as a broken bone) or permanent (such as blindness). Then, in concert with their student colleagues with disabilities, the students simulated similar disabilities with their own course schedules: opening doors with only one free hand, only using sidewalks where there were curb cuts, or trying to find handicap-accessible entrances to their classroom buildings.

Upon realizing the difficulties of navigating campus with a physical disability, the students began their social change action plan: developing a map of accessibility on campus for the Access Center's use. The Access Center community partners indicated that such a map had been a project in the works for their office, but recent changes to campus architecture as well as limited resources had made completing the map difficult. The students mapped every exterior door, elevator, and ramp on campus, indicating how a student with a physical disability might best access each building. The Access Center then took their data and partnered with website designers to make an interactive map of campus accessibility, which they continue to use as a reference for their student clients.

The second student group was interested in answering the question, "How welcoming is the Manhattan, Kansas community for its Muslim citizens?" These students partnered with the local Islamic Center: they toured the facility and gathered the stories of local Muslims. In interviewing their community partners, they found that many of the city's Muslim residents felt comfortable and safe in the community, and that they were often shown overt support during times of crisis, such as following 9/11, when Muslims in other communities were targeted for acts of bias. However, the respondents did mention that they would like to see more engagement all throughout the year, not just when students have assignments or when there is a crisis.

The students were inspired by their time at the Islamic Center to create an on-campus student chapter of the Interfaith Youth Corps, an organization devoted to fostering interfaith dialogue and building an appreciation for religious pluralism (IFYC, 2017). Such a group was intended to provide meaningful connection to the Islamic Center and other on- and off-campus religious groups. During its two years of activity, the organization sent students to a national interfaith training and held several dialogues on campus and in the community to build religious understanding.

These two examples best represent the potential for the CBAR to help students grow in their intercultural leadership capacity while creating inclusive social change. That said, though several CBAR products meet or exceed my expectations, not all do; I will explore the limitations of the CBAR in the discussion section. 


\section{Discussion and Conclusion}

As a cornerstone assignment that spans the length of the entire term, the CBAR has generated deep student learning around inclusive leadership. Regardless of the level of success in terms of grade, group dynamic, or social change activity, most students could reflect on how the CBAR gave them the opportunity to hear stories they might otherwise have never heard. Through engaging with diverse constituencies, students had the opportunity to expand their inclusive leadership capacities, familiarizing themselves with the challenges various groups in their communities face.

The multicultural leadership course also encourages students to foster inclusive social change through leadership action; CBAR has the potential to meet this objective as well. As evidenced by the two examples mentioned above, some students are so moved by the data they gathered that they felt compelled to act beyond the formal parameters of the class. The relationships some students develop through the CBAR persist after the assignment is completed, leading to continued dialogue and increased capacity to create change.

Simultaneously, in addition to supporting the course's learning outcomes of developing appreciation for others and engaging in inclusive social change, the assignment has the added benefit of giving students an opportunity to practice leadership with one another in CBAR group learning communities. Students reported some of the most powerful inclusion lessons stemmed from their interaction with their peer colleagues in navigating the assignment requirements, dividing work equitably, challenging each other's interpretation of data, or reconciling divergent schedules. Students had to meet the CBAR requirements to the best of their ability, but also reported they felt a responsibility to practice inclusion with one another. This feeling of shared responsibility frequently (though not always) led to more transparent work relationships, conscious efforts to share workload, and honest assessment of each group member's strengths in terms of meeting the shared goal of CBAR completion.

Limitations and Considerations for Change. Having employed the CBAR for three years now in my multicultural leadership class, I have found it to be a strong contribution to the curriculum as it endeavors to prepare multiculturally-competent leaders. That said, there are still some issues students and I have identified that could be addressed through revision of the CBAR for subsequent semesters. These reflections come from both instructor reflections and student narratives:

Decide how much methods knowledge - or what type of methods knowledge - is necessary. Few students in the course have statistical training or formal interview experience; a handful have no research experience whatsoever and have never even composed a literature review. There is a tension present in the CBAR between validity and parsimony. On one hand, if I am to ask students to engage in research, I want them to do it well - ethically, thoroughly, and with as much validity as possible. On the other hand, given the broad range of methods skills with which the students come into the course, the interdisciplinary nature of the minor attracting students from a variety of major disciplines with their own epistemological stances, and the fact that the course's learning objectives center not on methods competence but developing cross-cultural 
leadership skills, what is both realistic and appropriate in terms of methods sophistication for the CBAR?

About one in three groups chose to employ quantitative analysis of self-written surveys to gather data, but surveys have proven to be a problematic form of data collection for CBARs. Apart from sample size issues, which are notable, some students wrote survey questions whose outputs ended up telling researchers little about their constructs of interest. One group surveyed over fifty students to explore whether there was racial discrimination present in the university's sorority / fraternity system. However, only ten of their respondents belonged to fraternities or sororities - meaning the bulk of their respondents may not have possessed the local knowledge necessary to make an accurate judgment about the conditions of the sorority / fraternity system. As such, the average score on their response scale to measure perceptions of racism in the sorority / fraternity system was at the exact midpoint of the scale, telling them - and us, as their audience - next to nothing about their research question, even though the students met the stated parameters of the assignment.

In terms of the tension between methods and learning objectives, learning objectives should take precedence. Fortunately, groups who chose to employ quantitative methods differed little in their performance on the CBAR as compared to those who did not, as their reflection on the broader importance of their data or their literature reviews indicated a commitment to meeting the course's learning objectives. However, given the course's focus on appreciating subjective experiences, qualitative methods seem to be a better fit at any rate. To the end of providing students with more opportunities to engage meaningfully with diverse populations, I am considering mandating qualitative methods either interviews or ethnography - for future CBARs. Additionally, this would minimize the amount of methods training needed for students through the course.

\section{Forge intentional community partnerships for enhanced student learning.}

Between two sections of the multicultural leadership course, I coordinated sixteen student groups a semester. Inevitably, there was some overlap between courses in research questions of interest. For instance, I had three groups this past spring semester that were all interested in issues of physical disability. All three groups wished to partner with our on-campus office that works with students who have disabilities. By the time the third group contacted the center to arrange an interview, they understandably were met with a cool reception - the center's staff had their own students to work with, and they had already extended courtesies to two other groups from my courses. The CBAR does put the onus on campus and community partners to provide some of the educational support in the forms of time and materials. Unfortunately, I did not have the foresight to create intentional relationships with some community partners that I knew might be in high demand to prep them and draw up some mutually-agreed-upon guidelines outlining my students' involvement with their offices. I was guilty of violating the very "with" versus "for" ethos I had hoped to foster in my students by not laying an intentional framework in place with frequently-chosen community partners (Clayton, 2010). 
In developing future iterations of the CBAR, it will be necessary to balance student autonomy with structural constraints. The beauty of the current system is that students can self-select research questions - and, thus, community partners - of interest. But doing so, they run the risk of damaging relationships with on-campus units and besmirching the reputation of our academic program. One solution may be to experiment with "contracting" out some student campus offices that are typically in high demand for the CBAR. This will take more time and may compromise student autonomy, but it may lead to stronger collaboration and, thus, a better end product.

Evaluate the assignment's ability to foster social change. Though many groups develop and execute action plans based off thoughtful analysis of the data gathered through the CBAR process, not all groups are able to sufficiently address the inclusive leadership challenges their community partners surface. This gap between knowledge and action could manifest itself due to several factors. Some student groups have interpersonal dysfunctions that cause the CBAR focus to default more to the execution of the assignment than the higher-level goal of executing social change. Although group difficulties are fertile ground for encouraging students to think critically about leadership learning, the course goal of engaging in social change for others may not be met in such circumstances.

Still other groups may have difficulty engaging in social change within communities with which they may not identify. This speaks to the with / for tension of community engaged approaches to leadership learning (Clayton, 2010): if students are illeducated about inclusive leadership issues, do not yet have the multicultural competence to engage meaningfully with their target community partners, or view themselves as a benevolent outsider, then the capacity to change the social forces that create exclusive boundaries is hindered. Some CBAR groups create student organizations that persist beyond the course term; other groups submit action plans that advocate for little more than raising others' awareness regarding their research question. Such a wide range of commitment and success in student action plans indicate that some revision to the CBAR to better clarify the role of action in inclusive leadership could help students engage more meaningfully with their community partners to create improved conditions.

\section{Clarify links between action research, community-based research, and student}

leadership. Although I initially used action research and community-based research paradigms as the theoretical inspiration for the CBAR, what the students ended up doing could be considered superficial emulations of these approaches. As the course's learning objectives are not methods-focused, the CBAR may not have the capacity to devote enough time to methods to pay due respect to community-based and action research approaches. Further, the interdisciplinary nature of the academic program also means that I cannot assume a similar approach to research, not to mention understanding multicultural issues' significance when applied to leadership. Also, as this is a culminating final assignment, there is little carry-over in terms of lasting action for most groups that complete the CBAR. Although some student groups create useful, lasting artifacts or form persistent co-curricular organizations, such examples are more the exception than the rule. 
As the instructor of the course, I wrestle with the academic honesty of claiming action research and community-based research as the intellectual frameworks of the CBAR. Are my students conducting true community-based research if they are not immersing themselves in the communities they study beyond the timespan of a term? Is it truly action research if community partners are not invited to hear their presentations and if the students themselves are not inspired enough to share their action plans themselves with those with whom they worked? Keeping the CBAR a component of the multicultural leadership course's curriculum has helped students better meet the learning objectives of the course, but constant evaluation and reflection is necessary to ensure that student learning, community needs, and best practices are all promoted.

Conclusion. Inclusive leadership calls on its practitioners to create the conditions by which all have the potential to thrive. The CBAR serves as a scaffold for the students in my multicultural leadership class, giving them the opportunity to immerse themselves in diverse social contexts to hear the challenges, barriers, and opportunities others in their community face. The assignment's primary strength lies in its ability to place students in face-to-face conversations with others, which then gives them the chance to practice the skills necessary to exercise inclusive leadership. Additionally, the CBAR calls students into action, asking them to create social change that addresses the inclusion gaps their data unearthed. Although the assignment has limitations, it is the CBAR has the potential to move students toward practicing inclusive leadership dynamics.

\section{References}

Berger, P.L., \& Luckmann, T. (1966). The social construction of reality: A treatise in the sociology of knowledge. Garden City, NY: Anchor.

Bird, A., \& Osland, J.S. (2006). Making sense of intercultural collaboration. International Studies of Management \& Organization, 35(4), 115-132.

Burawoy, M. (2005). For public sociology. American Sociological Review, 70, 4-28.

Choo, H.Y., \& Ferree, M.M. (2010). Practicing intersectionality in sociological research: A critical analysis of inclusions, interactions, and institutions in the study of inequalities. Sociological Theory, 28(2), 129-149.

Chrislip, D.D., \& O'Malley, E. (2013). For the common good: Redefining civic leadership. Wichita, KS: KLC Press.

Clayton, P. (2010, July 16). The power of little words. Retrieved from https://static1.squarespace.com/static/51a00182e4b00ebfe3c66f62/t/52119d62e4b064b5b 5eec91c/1376886114924/The+Power+of+Little+Words.pdf

Cullen, M.J. (2008). 35 dumb things well-intended people say. Garden City, NY: Experts Academy Press. 
Dallimore, E., Rochefort, D.A., \& Simonelli, K. (2010). Community-based learning and research. New Directions for Teaching and Learning, 124, 15-22.

Fine, L.E. (2017). What's in a word? Troubling and reconstructing the discourse of inclusion. In A. Boitano de Moras, R.L. Dutra, \& H.E. Schockman (Eds.), Breaking the zero-sum game: Transforming societies through inclusive leadership (pp. 29-42). West Yorkshire, UK: Emerald.

Fine, L.E. (2015). Teaching multicultural leadership using a social constructionist approach. Journal of Leadership Education, 14(2), 209-217.

Fontaine, S.J. (2006). Integrating community-based research into the curriculum. Journal of Higher Education Outreach and Engagement, 11(2), 45-56.

Goodman, D.J. (2011). Promoting diversity and social justice: Educating people from privileged groups. 2nd ed. New York: Routledge.

Holt, K., \& Seki, K. (2012). Global leadership: A developmental shift for everyone. Industrial and Organizational Psychology, 5, 196-215.

IFYC. (2017, 7 June). The framework. Retrieved from https://www.ifyc.org/about

Karim, A.U. (2003). A developmental progression model for intercultural consciousness: A leadership imperative. Journal of Education for Business, 79, 34-39.

Kimmel, M. (2002). Toward a pedagogy of the oppressor. Tikkun, 17(6), 42.

Komives, S.R., Lucas, N., \& McMahon, T.R. (2013). Exploring leadership: For college students who want to make a difference. 3rd ed. San Francisco, CA: Jossey-Bass.

Komives S.R., Wagner, W., et al. (2009). Leadership for a better world: Understanding the social change model of leadership development. San Francisco, CA: Josssey-Bass.

Kuh, G.D. (2008). High-impact educational practices: What they are, who has access to them, and why they matter. Washington, DC: AAC\&U.

Li, M., Mobley, W. H., \& Kelly, A. (2013). When do global leaders learn best to develop cultural intelligence? An investigation of the moderating role of experiential learning style. Academy of Management Learning \& Education, 12(1), 32-50.

Lisak, A., \& Erez, M. (2014). Leadership emergence in multicultural teams: The power of global characteristics. Journal of World Business, 50, 3-14.

Marcuse, H. (1964). One-dimensional man: Studies in the ideology of advanced industrial society. Boston, MA: Beacon Press.

Ruderman, M.N., \& Ernst, C. (2010). Finding yourself: How your social identity affects leadership. Leadership in Action, 30(1), 14-18. 
Sagor, R. (2011). The action research guidebook: A four-stage process for educators and school teams. 2nd ed. Thousand Oaks, CA: Corwin.

Soria, K.S., Snyder, S, \& Reinhard, A.P. (2015). Strengthening college students' integrative leadership orientation by building a foundation for civic engagement and multicultural competence. Journal of Leadership Education, 14(1), 55-71.

Stringer, E.T. (2014). Action research. 4th ed. Los Angeles, CA: Sage.

University of Maryland Division of Student Affairs. (2015). Designing quality service learning courses. Retrieved from http://thestamp.umd.edu/leadership_community_servicelearning/academic_opportunities/faculty_service-learning/designing_quality_servicelearning_courses

\section{Author Biography}

Leigh E. Fine has taught graduate and undergraduate courses related to multicultural leadership, ethics in leadership, peer leader development, and foundations of leadership. His scholarly interests include leadership pedagogy, assessment, queer theory, social construction, and intersections of gender and sexual identity. Email: leigh.e.fine@gmail.com 